\title{
Significance of Point, Line and Plane in Teaching of Modeling Basis of Design Discipline
}

\author{
Lili Tan \\ Design School, Jilin Animation Institute, Changchun, 130012, China
}

Keywords: Point. Line and plane. Design discipline. Modeling. Teaching. Significance

\begin{abstract}
At the beginning of teaching of design major, i.e. during the teaching of modeling basis, the professional teachers should try their best to teach the college students to apply basic elements such as point, line and plane to complete the works they designed, and take different teaching means to improve the creation ability of college students, making the insignificance symbols such as point, line and plane can really make use of its great value. In this paper, the author defines the meaning of point, line and plane, and explains the significance of point, line and plane in the teaching of modeling basis of design discipline from the representational morphology significance, expressive morphology significance and abstract morphology significance.
\end{abstract}

\section{Introduction}

The research on the modeling elements such as point, line and plane has always been the top importance in the teaching of design major in higher institutes. However, in recent years, except that the famous artistic higher institutes with large reform range include them into the learning scope of modeling course, the research on point, line and plane is not emphasized in the basic modeling discipline of design major in a majority of the remaining ordinary institutes. In turn, it is unavoidable to cause the disconnection and lack of connection between the design basis and the basic modeling course, thus causing that the learning course of the college students is too boring, and even it is unable to get the relation between the point, line and plane and other learning contents, so it is impossible to form a systematic and prudent knowledge system. In the teaching of design major of higher institutes, it is required to emphasize the impartation and application of basic point, line and plane knowledge definitely and penetrating this research into the basic modeling teaching system of design discipline cannot only enhance the mutual connection between the professional basic knowledge and the modeling knowledge, but can also solve some problems that are difficult to be explained clearly in the professional basic course in the basic modeling course, so as to reduce the pressure of professional basic course invisibly.

\section{Definition of point, line and plane}

Point is the smallest basic morphology, and also the simplest morphology, being an inseparable important element in all arts. It is various points that construct the line jointly, and the lines combine with lines to form plane. As a result of the above causal relationship above, it is able to see the quite rich visual images. So it can be seen that point is the smallest but an inseparable important element in all visual arts.

Line is generated from point. If point is the parent, then line is the child. According to different feelings, the line can be roughly classified into the following: straight line is the line with a strong directionality, horizontal line is a line of cold morphology, vertical line is a line of warm morphology, arbitral straight line is a line with irregular cold and warm morphologies, while curve is the stream with the characteristics of circles. However, only under a specific condition will the curve generate circles; the spiral line is very strange, the largest difference between it and the straight line and curve is that it symbolizes the rule of universe permanence, and has and endless sense, being a line with great expressive force. 
Plane must be constructed with length and width. There are countless varieties of planes, not only including the regular rectangle or square. For any closed plane, no matter how complex it is, as long as multiple lines constituting the plane can be closed, the closed plane can be understood as a plane. So it can be seen that the plane must be a complete figure first. Although there are no laws for some planes and seem to be quite arbitral, the boil down to a closed figure.

\section{Specific significance of point, line and plane in the basic teaching practice of modeling of design discipline}

\section{Representational morphology significance}

Through the mutual combination of three-dimension and plane and the combination $\mathrm{f}$ tradition and modern, it is able to create a representative morphology like dream. However, in the teaching of design discipline of higher institutes, this is not the common means. In the hand painting of college students, once it is unable to innovate the creation means of classical design, in the future study, the conception, composition and representation means of the works designed by college students will be lack of the meanings of the traditional culture, and they are easy to be lost in the ever changing design tend. In the learning of combination of three-dimension with plane, it is required to earnestly research the transformation of three-dimensional image and plane image, make college students learn to appreciate, understand and analyze the three-dimensional works and master the creation concept of the works through teaching. In the selection of creation thought, it is required to fully consider the mutual link and transformation between the new image and old image, traditional image and modern image, so as to make the college students innovate the conception and image selection of their own works. In consideration of this, in the teaching of modeling basis, it is required to introduce the classical contents to students intuitively and vividly. For example, the works of Mr. Wu Guanzhong do not only have the romantic charm of the oriental art, but also have the presentations in materials and conception, seeming to be free. Through such learning, college students can somewhat comprehend and can also understand the important value of the basic elements such as point, line and plane.

In the representational image, the point, line and plane seem to be quite abstract, however, the point, line and plane in the abstract image seem to be representational. Therefore, when teaching the students creation of representational morphology, it is required to make college students mine the sense of abstraction of image constructed under the appearance of representation, so as to make them discover the abstract point, line and plane hidden in the skeleton of the image, and carry out meticulous organization. For example, when setting the design sketch course for the freshmen, the author will inevitably arrange the contents of static painting, and this requires the college students to accept or reject the image details freely according to the image profile or the profile of things. Although the final result of the image is still the readable representational morphology, it is required to implement free conversion in the alternating of point, line and plane between morphologies and in the morphology itself, but not do copy the original appearance of things stiffly. Once placing a set of jars with basically consistent height and size, I would require the students to outline a group of sketches formed by the point, line and plane, and then select the drawing most appropriate to represent these static things for earnest depiction. Meanwhile, the college students are also required explore the special composition of jars with not outstanding front and rear space senses or regularity of static things during outlining. In the image organization and arrangement, it is also possible to require the college students to simplify the quite complex tone and profile, more highlight the point and line in the pictures and make the style of picture more coordinated.

\section{Expressive morphology significance}

For the significance of expressive morphology, its generation is inseparable from the teacher's teaching on how college students should think. The author thinks that it is required to make college students think actively, while thinking is from accumulation, so it is extremely important to enhance the introduction to the artistic form of the east and west in the basic modeling course. In the traditional art of the east and west, a lot of artistic forms are used to express the meaning but not to 
describe things, that is to say, the artistic forms do not take the realistic painting as the representation method, but to create a new road of writing uniquely. For example, in the freehand brushwork in traditional Chinese painting, cursive handwriting and running hand works and the expressional-school works in the western art, the purpose of creation is to emphasize the author's unique understanding to life and universe, that is, to blend the soul of things with the soul of creator, i.e. although the works themselves are through or by virtue of the description of things, due to the free form and exaggerated and bold image, such works are often an expression method for the creator to represent his inner world to the outside. It is because of the originality and non-reproducibility of expressive morphology that it has a very strong sense of visual impact, so as to make a strong impression that cannot be effaced to the appreciators. Therefore, learning and classics in the traditional art of the east and west and taking them for reference can improve the college students' appreciation ability and creation representation ability indeed.

As we all know, sub-consciousness brings strong vitality and continuous creation energy for various representation forms of the modern people. The human sub-consciousness has the characteristics of commonness and uniqueness. Therefore, it is not only required to deeply inherit and mine the representation forms created by the predecessors in the sub-consciousness, but also stimulate the college students' sub-consciousness according to their actual condition, so as to get the opportunity of reveal talents. To make use of the visual symbols and visual habits of college students in different individual characteristics, it is required to cultivate them according to their personality and hobbies and make them grow freely. During teaching, it is required to exhibit the masterpieces of famous painters or designers who successfully blend the sub-consciousness into the image, for example, the Starry Sky and Self-portrait of Van Gogh did not only have rich objective materials, but also includes the painter's life experience and the their deep understanding to the universe life subconsciously, with an impulse and passion that are difficult to be restricted, and the flowing and living lines in the picture were sure to be from the unique and sensitive hart of Van Gogh. Therefore, it is required to deeply guide and enlighten the students to actively mine and apply their own unique sub-consciousness to carry out artistic design.

\section{Abstract morphology significance}

In the teaching practice, the author hopes that the teaching reform should be changed in the link of abstract morphology, while the modeling basis teaching and morphological tectonics in the deign discipline are mutually blended. Although there has been no complete and systematic teaching plan in the teaching of design major of higher institutes, the author has always been thinking how to organically run the teaching contents of this part through the modeling basis teaching in recent years and make it possible to combine the two courses. The two courses themselves are still relatively independent, but labor division and cooperation are completely available, so as to achieve mutual connection and help. For example, it is required to make students the apply the knowledge on point, line and plane learnt in the morphological tectonics to the basic modeling image more flexibly, so as to avoid the only use of elements such as point, line and plane lack of vitality; while during the basic course of design, it is required to set aside of such classical point, line and plane law and not to arrange the position, size and alternation relation in sketching etc. The author feels that to comprehensively avoid the unbearable situation of lack of mutual link between the basic courses of various design subjects, it is required to closely combine the morphological tectonics and the basic modeling course. Only in this way can the college students really create works with the significance of abstract morphology.

In the teaching of morphological tectonics simultaneously carried out with the basic teaching course, college students can understand the knowledge in the construction of relevant points, lines and planes and various morphological tectonics laws such as balance, symmetry, gradual change and contradictory spaces through the teachers' teaching more intuitively and deeply, and meanwhile, and meanwhile, they can also complete the practice of courses in various stages according to the teaching requirements. However, in the realistic teaching, students often seem to be casual in the selection of design elements, or seem to be too obsolete or the same, so they cannot create novel and unique morphological tectonics works. When appreciating the painting or design masters' works, we will 
often praise them for their deep observation life and their strong expressive force, because these works have an extremely strong life flavor and very exquisite modeling skills, while they are just what the contemporary college students are lack of. In consideration of this, it is required to bring the concrete and vivid images in the basic modeling course and the perceptual observation and understanding of college students to life to the class of morphological tectonics, and then restore the life elements obtained through rational analysis to the works created in the basic course class comprehensively, so as to form a very complete and quite beneficial cycle. In this way, it is able to bring vitality and energy to the teaching of morphological tectonics, and meanwhile, it is also possible to bring excellent works rationally summarized and analyzed to the teaching of modeling basis. For example, the figures like point, line and plane in morphological tectonics are often constructed by the abstract point elements in the tectonics, but what we do not know is that the small but circular morphology or a lot of irregular small figures can also be called point in the graphics. Therefore, once it is required to bring the observation, sketching and summarization to the static things to the teaching and creation of morphological tectonics in the modeling basis teaching, the college students will be able to create figures composed of point, line and plane with life flavor really. For example, we can make a lot of morphologies with the characteristics of points in static things into point figures, so as to improve the sense of form of the pictures continuously. No matter how many differentiated morphologies in the creators' images, the images can be constructed with this element, and the corner angles, straight line and curve etc. of the original object can be decomposed into point elements. So it can be seen that the morphological tectonics and the teaching of basic modeling course can be of mutual connection, penetration and support completely. Of course, there are also many representation forms for the construction form in the morphological tectonic, which can be interconnected with the basic modeling course. Therefore, the author feels that it is able to arrange the teaching in the same period according to the commonness of the two courses completely, and meanwhile, it is also expected that this teaching reform can be continuously perfected in the later class teaching of design major, so as to form a set of more complete mode of course intercommunication.

\section{Conclusion}

As stated above, in all visual artistic forms, the smallest unit is no doubt point, while the movement locus of point form lines and the lines are enclosed to form planes. Therefore, all visual arts are constructed through countless regular or irregular points, lines and planes. Thus, point, line and plane become the basic elements of all artistic forms, which have rich and colorful composition methods, while the different points, lines and plane construction forms can express different feeling information. Therefore, the students majoring in design in higher institutes should learn to digest through the learning of point, line and plane and other modeling factors, and combine the knowledge with their own design creation, so as to achieve great success in the road of artistic design.

\section{References}

[1] Hong Ying, Reform of Model Basis Teaching in Design Major of Higher Institutes [J]. Education and Occupation, 2010 (29)

[2] Zhang Ning, Fantastic Ideas-Cultivation of Innovative Thinking in Teaching of Design Modeling Basis [J], Journal of Inner Mongolia Normal University (education science), 2011 (11)

[3] Li Li, Discussion and Practice on Teaching of Basic Modeling Course of Artistic Design Major, [J], Decoration, 2012 (8)

[4] Zhang Rui, New Morphological Design: Research on Teaching of Modeling Basis [J] Research on Art Education, 2012 (21)

[5] Zhao Ting, Exploration on Teaching Reform of Basic Design Modeling Course [J], Art Panorama, $2013(12)$ 